\title{
Six Theses About Pleasure
}

In this essay I defend six theses about pleasure:

1. 'Pleasure' has one English antonym: 'unpleasure'.

2. Pleasure is the most convincing example of an organic unity.

3. The "hedonic calculus" is a joke.

4. An important type of pleasure is background pleasure.

5. Pleasures in bad company are still good.

6. Higher pleasures aren’t pleasures (and if they were, they wouldn’t be higher).

I devote one section to each thesis. The sections are fairly self-contained and may be read separately, so read what looks interesting. The first section is merely terminological, but the others defend substantive claims about pleasure.

\section{Thesis 1: 'Pleasure' has one English antonym: 'unpleasure'.}

Sometimes philosophers forget how widely ‘pleasure’ is used. Perry’s little-read book, now almost forty years old, can remind us. Perry says that 'pleasure' can ordinarily refer to: states of consciousness; innocent diversions; sensual indulgences; what one chooses; and sources

of pleasure. ' I'll use 'pleasure' to refer to states of consciousness. More specifically, I'll use it to 
refer to states of consciousness that are desirable merely as feeling. Some philosophers have found this usage unnatural. Mayerfeld, for instance, echoes Sidgwick in his complaint that "[i]n everyday talk, pleasure tends to mean gratification of the senses." ${ }^{\text {,ii }}$ He evidently has in mind Perry's third use of 'pleasure' (“sensual indulgences”), but the first is also circulating.

Perry says that 'pleasure' lacks a strict antonym. ${ }^{\text {iii }}$ And indeed, philosophers have contrasted pleasure with various things, none of them quite right. 'Unhappiness' is too narrow. It suggests a non-transient state with important emotional and cognitive elements. So someone who stubs their toe gets the opposite of pleasure but need not be unhappy. 'Displeasure' has the defect of connoting disapproval. It is the antonym, not of pleasure, but of being pleased. Those who think that pleasures essentially involve an attitude towards a sensation won't mind the connotation. ${ }^{\text {iv }}$ However, a true antonym of 'pleasure' should be neutral on this issue, since 'pleasure' is.

Ethicists have traditionally spoken of "pleasure and pain," but the differences between them are well known. 'Pleasure' includes the greatest array of positive experiences, but 'pain' ordinarily means "physical pain" and thus excludes anxiety, humiliation, terror, and so on. 'Pain’ typically excludes some bad physical experiences as well, such as itches, aches and exhaustion. Moreover, if states are of the right phenomenological type, we normally call them "painful” even if they're not bad. Pains that have been completely neutralized by analgesics, for example—pains we don't mind having—are still pains, but if a pleasure becomes neutralized, it’s no longer a pleasure. Hedonists often stipulate 'pain’ to mean “the opposite of pleasure,” but some confusion will result from this, especially as more and more philosophers of cognitive psychology use 'pain' in the ordinary way. 
Some two-word phrases come close. 'Disagreeable feeling' contrasts with 'pleasure' but suggests a theory of what makes experiences bad. The idea that a feeling is disagreeable insinuates that one's cognitive or affective reaction to it—one's disagreement with it—makes it bad. 'Pleasure' is not like that. 'Unpleasant experience' is closer still to being antonymous with 'pleasure'. However, there is at least one disanalogy. Recall Sidgwick's distinction between pleasure intensity and sensation intensity: "a pleasant feeling may be strong and absorbing [= intense as a sensation], and yet not so pleasant as another that is more subtle and delicate [= mild as a sensation].”v Pleasant experiences are paradigmatically mild as sensations and pleasures. Paradigmatically, taking a leisurely stroll on a nice day (without your cell phone) is pleasant; the feeling is "subtle and delicate" but hopefully not the best pleasure you'll ever know. Similarly, unpleasant experiences are typically not too bad and not too phenomenologically "busy," whereas pleasures may be intense and absorbing. Now admittedly, the semantic tendency of 'unpleasant experience' to refer to subtle and delicate sensations is not too strong; it does not seem unnatural to say, “That roller coaster ride was very unpleasant,” even though it produced very intense sensations. However, it does sound like understatement to say "Torture is extremely unpleasant" because torture is so intense as a—as, well, whatever the opposite of pleasure is.

'Pleasure' does have an antonym: unpleasure. If you don't believe this is a word, look it up. Philosophers have unwisely let it belong solely to Freudian psychoanalysts. As they die out, we should keep it going. Unlike ‘displeasure’, ‘unpleasure’ doesn't entail or connote dissatisfaction. And unlike 'pain', unpleasures include all the unfavorable experiences. 'Unpleasure' is a useful English word. 


\section{Thesis 2: Pleasure is the most convincing example of an organic unity.}

Something has intrinsic value just in case its existence wholly accounts for the existence of that value. Intrinsically good things are good in themselves; the circumstances don't matter. An organic unity, as defined by Moore, is an intrinsically good thing whose value differs from at least one way to sum the intrinsic values of its parts. ${ }^{\mathrm{vi}}$ This definition assumes that the parts fully compose the whole and don't overlap. The organic unity might have more, or less, intrinsic value than its parts. When it has more-as in most alleged unities—-the parts' coming together results in a synergy of intrinsic value. Moore, for example, believed that a synergy results when one becomes conscious of a beautiful object; the consciousness of the object, he thought, has more intrinsic value than that of the object plus that of being conscious. ${ }^{\text {vii }}$

Organic unities have been widely discussed, sometimes in the guise of discussing whether value is additive. viii However, the best candidate for organicity has been overlooked: ordinary episodes of pleasure and unpleasure. ${ }^{\text {ix }}$ Pleasures seem more intrinsically valuable than the summed values of their parts. Which parts? This depends on whether pleasure phenomenology is intrinsically good, or whether the phenomenology needs something else to be good. I wrote a paper on this question but won't assume I got the answer right. ${ }^{\mathrm{x}}$ Instead I'll show that pleasures seem organic either way.

First, suppose that something else is required to make the phenomenology pleasurable. If so, then the phenomenology alone wouldn't have intrinsic value (on my view, anyway), so it couldn't be an organic unity. However, the phenomenology conjoined with whatever makes it good would be organic. Suppose, for example, that one must like one's conscious state for it to be pleasurable. Then the conscious state conjoined with one's liking it would be intrinsically 
good, and intrinsically good out of proportion to its parts. After all, the conscious state, and the attitude, in isolation, would have little or no value; only when they come together would there be pleasure. If this is the correct hedonic metaphysic, then all pleasures and all unpleasures are organic unities.

Suppose instead that the goodness of pleasurable states is wholly explained by their phenomenology. Phenomenological episodes are events with temporal parts, including very brief parts. A minute of pleasure, for example, consists of sixty million events each lasting onemillionth of a second. Can a phenomenological event lasting a millionth of a second have intrinsic value? It might have value simply qua consciousness or qua mental state. But if that's all, then the value of its parts would not sum up to the value of the whole, since the minute would have value qua consciousness or qua mental state plus hedonic value (value qua feeling). So the relevant question is this: can a phenomenological event lasting a millionth of a second have intrinsic hedonic value?

If it can't, then an intrinsically good minute of pleasure is an organic whole, composed of sixty million intrinsically hedonically neutral parts. And so all pleasures and unpleasures—all hedonically valuable experiences—would be organic wholes.

But perhaps a tiny duration of pleasure does have value, just not very much. This idea may seem absurd to those who think that phenomenology needs an attitude or affective state to be good, since an event lasting a millionth of a second goes by too fast for us to have attitudinal or affective reactions to it. However, even those who think that pleasure phenomenology is intrinsically good might deny that very brief stretches of phenomenology can have value, for either of two reasons. First, perhaps a millionth of a second is not enough time for a mental state to be experienced. I won't try to assess that claim, but it is superficially plausible. Second, 
perhaps the pleasurableness of a phenomenological state consists of multiple phenomenological elements, each of which is insufficient for hedonic value. (These elements might vary, depending on the type of pleasure.) During a short enough time period, these elements might not coexist - and so a pleasure might be an organic whole consisting of temporal parts too small to contain all the requisite elements. Or perhaps the minute of pleasure is an organic whole whose relevant parts are phenomenological elements existing at a single time, each insufficient for hedonic value, but sufficient together. If so, again pleasures are organic.

These are difficult issues, but almost everyone will think that pleasures and unpleasures are organic for one reason or another. Hedonic value provides the most convincing examples of organicity because pleasures and unpleasures are the most widely accepted bearers of intrinsic value. ${ }^{\mathrm{xi}}$ In general, if you can make your point with pleasure, then do so.

\section{Thesis 3: The "Hedonic Calculus" is a joke.}

Analytic philosophers envy the rigor of science. Nowhere is this more evident than in references to "the hedonic calculus." We should stop using that bombastic, misleading phrase, for several reasons.

First, note that if there were a hedonic calculus, it would involve grade school arithmetic, not integrals and derivatives. The hedonic value of an outcome would be the sum of products; to find it, multiply the intensity and duration of each pleasure and unpleasure in the outcome and sum up. If the hedonic calculus extends to actions, then value would be determined by the formula for expected utility. This is also about product summing: to find the hedonic value of 
an action, multiply the probability of each possible outcome by its hedonic value and sum up. True, one definition of 'calculus' is “any method of calculation”- —not just the method invented by Newton and Leibniz_-but to my ear “the hedonic calculus” still carries pretensions to higher math.

The idea of this calculus implies that hedonic value can be precisely quantified. And indeed, philosophers often cite pleasure as paradigmatically susceptible to quantification. ${ }^{\text {xi }}$ Many utilitarians talk in this way. Bentham instructs us to "[s]um up all the values of all the pleasures on the one side and those of all the pains on the other."xiii According to Mill, "the truths of arithmetic are applicable to the valuation of happiness, as of all other measurable quantities.”xiv And similarly, Sidgwick says, “all pleasures ... are capable of being compared quantitatively with one another and with all pains ...”xv

There are several sophisticated objections to this idea:

- Perhaps exact numerical relations don’t exist between phenomenologically disparate pleasures. For example, there may be no fact of the matter as to whether this token of pleasurable taste is better than that token of fond remembrance. If so, then precise numbers can't be put on these experiences, at least for the purpose of comparing them to each other. ${ }^{\text {xvi }}$

- Some ethicists think that "hedonically better than" isn't transitive; in other words, some states of affairs A, B and C are such that B is hedonically better than A, C is hedonically better than $B$, but $C$ is not hedonically better than $A .{ }^{\text {xvii }}$ If so, then numbers can't accurately represent their hedonic values (at least for the purpose of comparing them to 
each other) since this would require B's number to be higher than A's, C's number to be higher than B's, but C's number not to be higher than A's. This is impossible, since "higher number than” is indisputably transitive.

- Methods of calculation seem to break down in cases involving transfinitely many people and/or eternal lives. A countable infinity of suffering people seems less bad than those same people suffering worse, even though both outcomes seem to sum up to (or approach) the same order of negative infinity. And an eternal life of intense pleasure is better than an eternal life of mild pleasure, even though the value of each seems to sum up to (or approach) the same order of infinity.

- Some other objections apply to the simplest version of the calculus but perhaps not to more complex versions. For example, some ethicists think that the temporal concentration of unpleasure makes it worse (so, continuous pain in one life has more disvalue than an equal duration of similarly intense pain distributed among many lives). ${ }^{\text {xviii }}$ This idea runs against the atomistic nature of the calculus, but the quantitative effect of such concentration (if one exists) could presumably be factored in. Or Sprigge observes that some hours seem to pass more quickly than others. Are pleasures less valuable when they seem over sooner? And time, he reminds us, seems to pass more quickly in maturity than in childhood. Does a year's pleasure matter more for a child than for an adult? ${ }^{x i x}$ If such temporal factors affect value, perhaps the calculus could be amended to accommodate them. 
I won’t discuss these objections. My main criticism is more basic. First note that the idea of a “method” has some degree of success or effectiveness built into it; I can’t describe a method for stealing cars unless what I say could actually help someone steal a car (or something like that). We have no method for determining hedonic value, in my view, because what we have isn’t good enough. All known formulations of the hedonic calculus are non-starters as methods of assessing hedonic value.

How is the calculus supposed to work? How are we supposed to assign numbers to represent the hedonic value of states of affairs? The literature contains a lot of posturing and hand waving but little instruction about how to perform the calculations. When instruction is given, it usually goes something like this:

Suppose that someone in excruciating agony feels gradually better, improving at a constant rate, until she enjoys wonderfully intense pleasure. Identify a moment in this process when her conscious state is neither better nor worse than unconsciousness. Assign that state the number 0. Now work forward and backward in time, assigning her state five seconds after 0 the number 1 and five seconds before -1 . Then assign her state ten seconds after 0 '2' and ten seconds before 0 '-2,' and so on. These numbers represent the intensity of the base experiences. To confirm that the subject felt better at a constant rate, verify that she is indifferent among the following alternatives: having 0 for time $t$; having 1 and -1 for .5t apiece; having 2 and -2 for .5t apiece, and so on.

To determine the hedonic value of any state of affairs, order the experiences in it. Assign a number to represent the intensity of the first moment of experience by comparing it with the base. For example, if the first moment seems closest in intensity to 
the 8 pleasure, call it 8 . Continue down the line, assigning a new number each time the intensity changes — that is, each time it changes so much that it becomes closest to a different base experience. Notice how much time elapses between changes. Once you have finished, multiply each number by the duration of that experience, then add the products. The sum will represent the state of affair's overall hedonic value. ${ }^{\mathrm{xx}}$

All this might sound good, but it doesn't give us a method for assessing hedonic value. Let me explain why.

The procedure for assigning base numbers is problematic. It must be quite a rare event in history when someone in excruciating agony feels gradually better to the point of ecstasy. If the rate of improvement is really constant throughout, then probably this has never happened. So the procedure for setting base numbers must be a mere thought experiment. But if that's all it is, it's useless. The human imagination is inadequate to grasp exactly what experiences $-1,-2,-3$ etc. are all like, sitting in our chairs or lying in our beds. And even if we were more imaginative, different people would imagine the base subject's experiences changing at different rates, thus destroying the possibility of a publicly usable number system.

Also, we are told to confirm that the subject in this experiment felt better at a constant rate by verifying that she is indifferent among various alternatives. But how can do we this, when the “subject” doesn’t exist? One way or another, we'll have to fall back and then collapse on the crutch of our poor, strained imaginations.

To show how hopeless this enterprise is, suppose we have an idealized situation that we can’t have; suppose this were more than a thought experiment. Let's say you will be in agony, and somehow you know that you will be improving at a constant rate until you're in ecstasy. Further 
suppose you know that this will take an hour, and that in precisely 42 minutes your mental state will be perfectly neutral between pleasure and unpleasure. So you know that in 42 minutes your experience will be a 0 experience; in 42 minutes and 5 seconds your experience will be a 1 experience; in 41 minutes and 55 seconds your experience will be -1 ; and so on. So what? How in the future will even you be able to implement this "established” numerical system? We have no idea. Your memory is inadequate to the task; later you won’t remember, except vaguely, what -54 or 37 were like. Also, your vocabulary for describing experiences is unhelpful; it's not as if, while it's going on, you could describe what -54 is like in a way that will later let you identify other experiences as -54 rather than -55 or -51 . And your weak memory combined with your impoverished vocabulary can hardly do better than each can do alone. The agony-to-ecstasy thought experiment, even if it were actual, would not help us implement a hedonic calculus.

Sidgwick's chapters on hedonic assessment are wonderful. ${ }^{\text {xxi }}$ Today, when we try to gauge intensity, we can do no better than Sidgwick, who says:

when I reflect on my pleasures and pains, and endeavour to compare them in respect of intensity, it is only to a very limited extent that I can obtain clear and definite results from such comparisons, even taking each separately in its simplest form . . . This is true when I compare feelings of the same kind: and the vagueness and uncertainty increases, in proportion as the feelings differ in kind. ... And if this is the case with what Bentham calls 'pure' - i.e. painless-pleasures, it is still more true of those even commoner states of consciousness, where a certain amount of pain or discomfort is mixed with pleasure . . xxii 
So, comparing the base experiences to others would be difficult even if the same person is the subject of both, and even if the experiences aren't very complex. And don't forget that complexity is common. Adolescents, whose mental lives are typically more complex than adults', often have experiences so unusual and complex that it's hard for the teenager to tell, even approximately, what their value is.

Familiar problems also arise for assessing the experiences of others. Even if the implementer of the "method" has a good grasp of the base numbers, how could she judge the intensity-levels of others' experiences? There are ways, of course. We make estimates from others' vague qualitative verbal reports; from their revealed preferences; from their moans, groans, sighs, and how vulgar their curse words are; from the objective stimuli causing their experiences, when these exist, and so on. However, all this is imprecise, and often the implementer will have little of it to go on. Moreover, such problems are magnified when assessing the experiences of animals and infants. ${ }^{\text {xxiii }}$

Another fact makes the prospects of a calculus even dimmer. As I've formulated the "method,” we assign new numbers every five seconds when setting the base intensity figures. But numbers should probably be assigned more often. Arntzenius and McCarthy have proved that there can be differences in hedonic intensity too small to introspect. ${ }^{\text {xxiv }}$ Thus, there are probably thousands of different base levels that need to be represented with different numbers. And so our feeble imaginations, memories, vocabularies, and powers of judgment will be strained even worse as we try to implement the procedure.

Hence, we have no method for determining hedonic value; we have no hedonic calculus.

Have I been attacking a straw man? Perhaps no one thinks we actually have a calculus; it's just that there could be such a thing "in principle." I have several things to say about this. 
First, this may be what people think, but it isn’t what they say. People talk about the calculus as something that Bentham proposed, as something he put on the philosophical table, not as something he gestured feebly towards.

Second, if the claim is that human beings could in principle have a calculus-since the problems we now face are "merely technical”-then the claim is probably false and is certainly posturing. Today our position is even worse than Sidgwick’s: we haven't made any progress towards formulating a calculus, while the past hundred years have shown us more obstacles in our path. Could an increased understanding of neuroscience rescue our stillborn project? It could certainly be useful, but even a perfect knowledge of neuroscience would not automatically tell us anything. It's not as though unpleasure is identical to C-fiber firing, and all we have to do to assess intensity is to find some function involving the number of firings and their strengths. Rather, the neurophysiology of experience seems increasingly complicated, and to infer value claims from it would require judgment and guesswork as to what in the physiology is relevant, and in what way. So even then our problems wouldn’t be solved, just profitably reconceptualized.

Third, suppose someone says the idea is just that God could perform hedonic calculationsnot that we can, or ever will. That might be true, but it is hardly worth saying more than once, and it doesn’t seem to be what the references to Bentham are getting at.

In general, the way we discuss “the hedonic calculus” is misleading. Our actual methods of hedonic evaluation —if they are "methods"-are a hodgepodge of strategies in which judgment is prior to calculation and even simple assessments are often rough or inaccurate. 'The hedonic calculus'—-that swaggering, vainglorious phrase-has all the wrong connotations. We might wish that our methods were precise and “scientific”, but they aren’t.

The hedonic calculus is a joke. 


\section{Thesis 4: An important type of pleasure is background pleasure.}

Qualia are the qualitative or phenomenological aspects of experience: the way the ashtray looks, the way the cigar tastes, the way the ace of spades feels, the way the other players smell, and so on. When you're not in dreamless sleep, you enjoy (or sometimes you are subjected to) a continuous stream of qualia. This is what it means to sit in the Cartesian theater: there is something it is like to be you.

Most qualia, or most of their aspects, are in the theatrical background, unreflected upon, upstaged by more striking or salient experiences. As Leibniz says, the uniform sounds of a mill or a waterfall may be perceived but unnoticed because they are "too unvarying." "xxv I associate this phenomenon with air conditioners and dishwashers: I hear them but am not conscious of hearing them.

When we think of pleasurable qualia, we usually think of foreground pleasures. But background pleasures are more common. In fact, it is relatively rare for us to attend to our experiences.

Background pleasures have never, to my knowledge, been discussed as a class, but sometimes philosophers have had them in mind. Mill contrasts "the occasional brilliant flash of enjoyment” with “its permanent and steady flame."xxvi The brilliant flash sounds hard to miss—a foreground pleasure — while the permanent flame might go unnoticed, despite its continuous value. Mill’s steady flame may be Sidgwick’s “more indefinite kind of pleasure, which is an important 
element of ordinary human happiness, - - the 'well-feeling' that accompanies and is a sign of physical

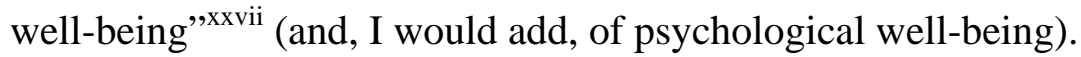

Background pleasures are not defined qualitatively. Like foreground pleasures, they can differ phenomenologically: unreflected upon joy differs from unreflected upon contentment or pride, and instances of these may vary in intensity. (Don’t think of qualia as moods; qualia are qualitative while moods—-for example, being cheerful or irritable—consist at least partly in behavioral dispositions.) Qualitatively distinct background pleasures also arise from different senseorgans. Oliver Sacks, for instance, quotes a patient who lost his sense of smell:

Sense of smell? I never gave it a thought. You don't normally give it a thought. But when I lost it—it was like being struck blind. Life lost a good deal of its savour—one doesn’t realise how much ‘savour’ is smell. You smell people, you smell books, you smell the city, you smell the spring — maybe not consciously, but as a rich unconscious background to everything else. My whole world was suddenly radically poorer. ${ }^{\text {xxviii }}$

This patient understood the value of background olfactory pleasures only after losing them. Background pleasures also arise from sight, sound, touch and taste (and probably from other modalities!).

Background qualia may also be unpleasurable in different ways; a background state may be depressed, anxious, bitter or painful. Such feelings come into the foreground more easily than background pleasures do. Unpleasures like to turn the mind inward.

In Plato's Philebus, Socrates condemns those who "think that at such times as they are not feeling pain they are feeling pleasure.”xxix But Socrates is too dismissive. Someone not in pain will 
always feel pleasure if her background qualia are always pleasurable. Physically and mentally healthy people may enjoy continuous mild pleasure in their waking hours. ${ }^{\mathrm{xx}}$ Aristotle did better when he said, “a neutral state is painful to many people because of their nature.”xxxi For even if one’s mental states are “neutral”—lacking significant foreground pleasures and pains_—one may feel pain if one naturally has unpleasurable background qualia: for example, if one is naturally depressed.

Nagel, I believe, misunderstands the phenomenon:

There are elements which, if added to one's experience, make life better; there are other elements which, if added to one’s experience, make life worse. But what remains when these are set aside is not merely neutral: it is emphatically positive. Therefore life is worth living even when the bad elements of experience are plentiful, and the good ones too meager to outweigh the bad ones on their own. The additional weight is supplied by experience itself, rather than by any of its contents. ${ }^{\text {xxii }}$

But a background hum of good feeling supplies the additional weight, not "experience itself.” For if experience itself had "emphatically positive” value, then all experiences would be very good in at least one respect; but dark episodes of depression lack any hedonic consolation. 


\section{Thesis 5: Pleasures in bad company are still good.}

Some philosophers think that pleasures are bad if they keep the wrong company. Such "bad" pleasures fall into four categories:

(A) pleasures taken in bad intentional objects (such as the belief that someone is suffering); ${ }^{\text {xxxiii }}$

"Suppose that I perceive or think of the undeserved misfortunes of another man with pleasure. Is it not perfectly plain that this is an intrinsically bad state of mind, not merely in spite of, but because of, its pleasantness?”xxxiv (Broad) Brentano, Ross, Brandt, Zimmerman, Yarnell, and Feldman agree. ${ }^{\mathrm{xxx}}$ Zimmerman says that such pleasures are “inappropriate” or “incorrect” under the circumstances. ${ }^{\text {xxxvi }}$

(B) pleasures accompanying bad behavior;

"Now since activities differ in respect of goodness and badness, and some are worthy to be chosen, others to be avoided, and others neutral, so, too, are the pleasures; for to each activity there is a proper pleasure. The pleasure proper to a worthy activity is good and that proper to an unworthy activity bad ...”xxxvii (Aristotle)

(C) pleasures that depend on false beliefs or cognitive error; 
"Suppose I believe, incorrectly, that my father has performed certain magnificent deeds and suppose I take pleasure in what I believe that he has done. . . . Brentano is clear that such a false ... pleasure is one that it would be better not to have—-this because of the intrinsic evil that error involves.”xxxviii (Chisholm)

(D) pleasures that people don't deserve.

"The sight of a being who is not graced by any touch of a pure and good will but who yet enjoys an uninterrupted prosperity can never delight a rational and impartial spectator. Thus a good will seems to constitute the indispensable condition of being even worthy of happiness.”xxxix (Kant)

Philosophers have also considered some unpleasures to be good: those taken in bad intentional objects; those accompanying bad behavior; and those that are deserved. Philosophers who believe the first typically say that displeasure taken in bad intentional objects is good. This may be for two reasons: 'displeasure' connotes disapproval, which is appropriately directed at bad things, and 'displeasure’ suggests mild unpleasure, while suffering always seems bad. Curiously, I don’t think anyone has endorsed the analogue of (C); no one has said that unpleasures are good which depend on true beliefs. But if (C) is true-if pleasures derived from cognitively defective sources are badwhy shouldn’t unpleasures derived from cognitively laudable sources be good? Perhaps philosophers who believe (C) also believe its analogue, even if they haven't said so.

Are (A)-(D) true? I'll focus on (A), to illustrate how I would treat them all. On (A), pleasures taken in the bad are bad. Or, if English isn't good enough, (A) says that schadenfreude is 
bad. But bad in what way? Lemos thinks that a pleasure's intrinsic value may turn on the value of its intentional object. ${ }^{\mathrm{xl}}$ If so, (A) might be amplified:

(A*) Pleasures are intrinsically bad that are taken in bad intentional objects.

$\left(A^{*}\right)$ must assume that the pleasure's object is intrinsic to the pleasure; for if it weren't, it (obviously) couldn't affect the pleasure's intrinsic value. Consider this reductio. Perfect duplicates cannot differ in intrinsic value; so, if a pleasure were intrinsically bad, extrinsically taken in the belief that Socrates had a miserable life, then a perfect duplicate of that pleasure would be intrinsically bad even taken in the belief that Socrates had a wonderful life.

Are intentional objects intrinsic to pleasures? They are, on some concepts of pleasure. For example, Lemos characterizes pleasure as "a state of affairs that implies pleasure and no pain." "xli If so, then Sonny Corleone took pleasure in believing that Carlo Rizzi suffered names a pleasure, since it entails the existence of pleasure (Sonny's) but not the existence of pain (since Rizzi might not have suffered). On Lemos' concept of pleasure, Sonny's belief about Rizzi would be intrinsic to his pleasure. This concept, however, is wildly permissive; on it, any state of affairs that doesn't entail pain would be intrinsic to countlessly many pleasures. For example, the fact that a coliseum exists would be intrinsic to the pleasure, Andy Kaufman was delighted as he ridiculed wrestling fans in the Mid-South Coliseum. Another, more natural, concept of pleasure also admits intrinsic intentional objects. If I say, "Eating chocolate is one of life's pleasures,” then a pleasure is, in that sense, a source of pleasure, or an activity that typically affords pleasurable experience. And my belief that this is chocolate, as I'm eating, might be intrinsic to this episode of chocolate eating. 
However, I am using ‘pleasure’ to refer to pleasurable experiences. So in asking whether intentional objects can be intrinsic to pleasures, I am asking whether, say, the sadist's belief that I'm suffering is intrinsic to the pleasure he takes in it. I won't try to answer this question, but the standard view is that beliefs are not intrinsic to experiences. So A*_-the idea that pleasure taken in bad objects is intrinsically bad-is suspect on metaphysical grounds alone.

(A) is better amplified as:

(A**): Pleasure’s being taken in a bad intentional object is intrinsically bad. (Here “pleasure’s being taken in a bad intentional object” names a state of affairs that entails the existence of both pleasure and a distinct intentional object. ${ }^{\text {xlii }}$ )

Why might $\mathrm{A}^{* *}$ be true? Not because “pleasure’s being taken in a bad intentional object” entails that a bad object exists, for it doesn't; if Lex Luthor believes that Superman suffered, he may take pleasure in that belief even if it's false. A** is probably motivated by:

(m) “Pleasure’s being taken in a bad intentional object” entails that an intrinsically bad relation exists, namely, an inappropriate way in which a pleasure and a bad object relate.

And supporters of $\mathrm{A}^{* *}$ will affirm one of the following:

(m1) “Pleasure's being taken in a bad intentional object” entails that pleasure exists, a state of affairs that is good; but its value is outweighed by the disvalue of the intrinsically bad relation's existing. xliii $^{\text {end }}$ 
(m2) "Pleasure's being taken in a bad intentional object" entails that pleasure exists, a state of affairs that is either neutral under the circumstances or that contributes disvalue to the larger state of affairs.

On (m2), pleasure’s being taken in a bad intentional object is an organic whole. As I said in section 2, the value of such wholes does not equal the summed value of their parts. Here the whole has less value than its parts, since the existence of pleasure does not contribute value to the larger wholeindeed it may contribute disvalue - whereas normally or in isolation the existence of pleasure is good.

Is $\mathrm{A}^{* *}$ true; is pleasure's being taken in a bad intentional object intrinsically bad? Carson thinks so, saying, "I am convinced by the arguments of Brentano and others," xliv but the literature lacks convincing arguments. Philosophers either assert $\mathrm{A}^{* *}$, offer $\mathrm{A}^{* *}$ as intuitively compelling, or assert (m1) or (m2) in support of $\mathrm{A}^{* *}$. ${ }^{\text {xlv }}$ I won't try to assess $\mathrm{A}^{* *}$. I'll restrict myself to discussing the value of pleasure, not pleasure relations, so I'll just argue against (m2) that pleasure is good even when taken in bad objects. ${ }^{\text {xlvi }}$

Nobody, to my knowledge, has argued that pleasures taken in the bad lack value. Many philosophers, however, find that view compelling, perhaps because "There is no sign more infallible of an entirely bad heart, and of profound moral worthlessness," as Schopenhauer says, "than open and candid enjoyment of seeing other people suffer., "xlvii But something good may accompany something bad. Sadists are bad people with ill intentions and contemptible characters-traits who repel peace-loving folk; ${ }^{\text {xlviii }}$ however, their pleasures may still be good (even if, for utilitarian reasons, they shouldn’t be praised). Moreover, taking intense pleasure in bad objects betrays an 
especially malevolent character; this explains why taking greater pleasure in the suffering of others seems worse, even if greater pleasure is better. ${ }^{\text {xlix }}$

How can we argue that pleasures are good even in bad company? Goldstein plumps for the value of undeserved pleasures as follows:

The distastefulness in a mass murderer retiring to days rich in undeserved pleasure seems to lie not merely in bad effects; his pleasure may seem intrinsically repugnant. Still, there is good even here. We denounce the pleasure because of its good; moral degenerates luxuriating in health, happiness, or long life seems repugnant for the same reason. ${ }^{1}$

This argument, however, is ineffective; those who deny that "there is good even here" will say: "I don't denounce the villain's pleasures because they're good. I denounce them because he enjoys them; and, for that reason, they're not good.” Here we have a standoff.

I offer this argument instead. Intense pleasure is good when taken in a neutral object (such as a silly joke), ${ }^{\text {li }}$ and intense pleasure is good that lacks any objects (as in generalized euphoria). Think of such pleasures that do not accompany laudable or culpable behavior; are neither deserved nor undeserved; and stem from neither error nor insight. These pleasures are good merely because they feel good. But, if so, then altering their extrinsic properties shouldn't affect that value. Therefore, pleasures are good irrespective of what they're taken in; of what accompanies them; of what they depend on; and of whether they're deserved. ${ }^{\text {lii }}$

Here is the best objection to the argument: "The pleasures of generalized euphoria are not 'good merely because they feel good.' They're good because they feel good and because they're not taken in bad objects. So, we can’t conclude that pleasures in bad company are good.” Response: 
"Given that such euphoria has no object, object-talk is irrelevant to its value. Its goodness resides in its feel; describing what it's like suffices to account for its value. And experiencing such pleasure suffices for us to understand its value."liii This response, I think, is better than the objection. If so, then the argument supports thesis 5: pleasures are good even in bad company.

\section{Thesis 6: Higher pleasures aren't pleasures (and if they were, they wouldn't be higher).}

As a young man, John Stuart Mill believed that pleasure is ultimately the only good thing. Later he changed his view, but he never changed his language. His use of 'pleasure' simply expanded to include everything he thought relevant to welfare.

In Utilitarianism, Mill supposedly endorses qualitative hedonism, the doctrine that some pleasures are qualitatively better than others. These so-called "higher pleasures" are superior to "lower pleasures," not because they're more intense or produce more push-pin utility, but because they're superior in kind. So, while Bentham cared only about the quantity of pleasure, Mill cared about its quality too.

However, this gets Mill wrong. Admittedly, Mill often talks as though pleasure is his topic. He certainly uses the word 'pleasure' a lot. But for him, the higher/lower distinction is not about pleasure, but about ways of life. He is not comparing different sensations but different "manners of existence":

Now it is an unquestionable fact that those who are equally acquainted with, and equally capable of appreciating and enjoying, both, do give a most marked preference to the 
manner of existence which employs their higher faculties. Few human creatures would consent to be changed into any of the lower animals, for a promise of the fullest allowance of a beast's pleasures; no intelligent human being would consent to be a fool, no instructed person would be an ignoramus, no person of feeling and conscience would be selfish and base, even though they should be persuaded that the fool, the dunce, or the rascal is better satisfied with his lot than they are with theirs. ${ }^{\text {liv }}$

This passage excites tough interpretive questions, but pleasure is clearly not Mill's topic. Few of us, he says, would become beasts, fools, ignoramuses, dunces or rascals in exchange for the pleasures of their ilk. And, indeed, few would. But many nonhedonic values influence this judgment. We prize many things that beasts and fools are short on: knowledge, virtue, grace, success, intelligence, compassion, wisdom, liberty, personal independence and power. ${ }^{\text {lv }}$ The intuitions Mill elicits concern greater well-being, not greater hedonic well-being. Pleasure is involved only in the idea that some things matter more than pleasure. The importance of other values explains why "[a] being of higher faculties . . can never really wish to sink into what he feels to be a lower grade of existence."’vi And when Mill attributes this preference to "a sense of dignity,"lvii this is not about the dignity of pleasures, but about dignified ways of life.

Thus, Mill’s doctrine is misnamed. It shouldn’t be called “qualitative hedonism.” A better, if clunky, name for it would be “qualitative welfarism.” It's not that some pleasures are better than others; it's that some modes of existence are better than others. And since

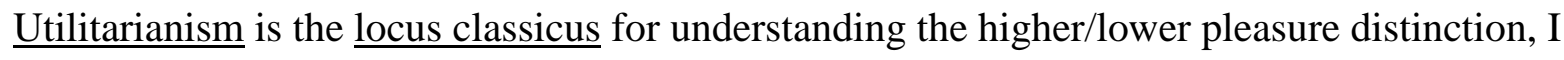
conclude that higher pleasures are not pleasures: they're ways of life. 
Let’s now use ‘pleasure’ normally. We can distinguish higher and lower pleasures in any of four ways.

First, we can define higher pleasures as those preferred by competent judges. For example, we can say that one pleasure is higher than another just in case most competent judges prefer it qua feeling. And we can add that those judges must be able to fully appreciate both pleasures and cannot base their preference on facts about duration or intensity.

There is a big literature on competent judges. However, none of it gives us any reason to think that such judges would recognize the existence of higher pleasures. If the judges truly focus on the pleasures themselves, ignoring all extrinsic factors, they may well care only about intensity and duration.

Second, we can define higher pleasures as those taken in "higher" things, while lower pleasures are those taken in "lower” things. The "higher" things are normally thought to be intellectual, moral, or distinctively human, while the corresponding "lower" things are bodily, immoral (or amoral?) and animalistic. On this definition, a higher pleasure is a pleasure that keeps good company: the company of higher objects. Thus the arguments of the last section apply here. Just as pleasures have a value that cannot be diminished by bad company, so they have a value that cannot be augmented by good company. I take no stand on whether pleasures combined with good company can constitute organic wholes.

Third, we can define higher pleasures as those taken in higher forms of behavior, while lower pleasures are taken in lower forms of behavior. (Here Moore’s example of a lower pleasure comes to mind: breaking the crockery while drunk. ${ }^{\text {lviii }}$ ) This suggestion is much like the second. The "higher" activities are thought to be intellectual, moral, or human; while the “lower” activities are bodily, immoral and animalistic. Higher pleasures are again keeping good 
company: that of higher behavior. And again, my arguments suggest that the pleasures themselves cannot get value from their concomitants, though together they may form an organic unity.

Fourth, we can define higher pleasures as pleasures that have an intrinsic advantage over lower pleasures, but not that of greater intensity or duration. This proposal comports with how qualitative hedonism is usually understood: higher pleasures are better, even when they're less intense.

This idea may seem puzzling, since it may seem impossible for a pleasure to be better qua experience without being more intense. Intensity, after all, is a broad evaluative notion; to say that a pleasure is more intense is just to say that it's better qua feeling. Thus, the notion of intensity may not seem to leave room for other intrinsic advantages. How could a pleasure be intrinsically better than another except as feeling?

Hutcheson provides a clue. He says,

We have an immediate sense of a dignity, a perfection, or beatifick quality in some kinds [of pleasure], which no intenseness of the lower kinds can equal, were they also as lasting as we could wish. ${ }^{\text {lix }}$

To me "a perfection, a beatifick quality" suggests beauty. Perhaps the superiority of higher pleasures is aesthetic. Higher pleasures aren't better qua feeling — better for the subject of the experience_-but aesthetically better.

This idea at least makes sense. Beauty is not just a property of music and faces; pleasures can be beautiful too. In fact, the pleasurable experience of hearing beautiful music or seeing a 
beautiful face is typically beautiful. (Perhaps we attribute beauty to music and faces because our experiences of them are beautiful?) I won't worry about whether beautiful pleasures closely correspond to the "higher" mental and moral pleasures, but they may not.

If the higher/lower distinction is merely aesthetic, it may seem to lack importance. Should we strive to have aesthetically higher pleasures, just so there will be more such things? Here we must ignore the fact that beautiful pleasures can provide pleasure; appreciating the beauty of our pleasures can make them more intense (or can provide different, pleasurable experiences). The more general form of this question is whether we should strive to create beautiful objects, irrespective of any pleasure they bring. I can’t do this question justice, but most philosophers would say no, and I agree.

In conclusion, I see no reason to think that so-called higher pleasures, however they are conceived, are really higher in the sense of being intrinsically better than so-called lower pleasures. ${ }^{\text {lx }}$

Stuart Rachels

University of Alabama 


\section{$\underline{\text { References }}$}

Almeida, Michael J.: Imperceptible Harms and Benefits (Dordrecht: Kluwer Academic Publishers, 2000).

Alston, William P.: “Pleasure,” The Encyclopedia of Philosophy, Paul Edwards, ed. (New York: Macmillan, 1964), pp. 341-347.

Aristotle: The Nicomachean Ethics, translated by David Ross, revised by J. L. Akrill and J. O. Urmson (Oxford University Press, 1980; originally long ago).

Arntzenius, Frank and David McCarthy: "Self Torture and Group Beneficence,” Erkenntnis 47 (1997), pp. 129-144.

Bentham Jeremy: The Principles of Morals and Legislation (1789), available in various reprintings.

Brandt, Richard (1): Ethical Theory (Englewood Cliffs: Prentice-Hall, Inc., 1959).

Brandt, Richard (2): A Theory of the Good and the Right (Oxford University Press, 1979).

Brentano, Franz (1): The Origin of Our Knowledge of Right and Wrong, Oskar Kraus, ed., English edition edited by Roderick M. Chisholm and translated by Chisholm and Elizabeth H. Schneewind (London: Routledge \& Kegan Paul, 1969; originally 1889).

Brentano, Franz (2): The Foundation and Construction of Ethics, Franziska Mayer-Hillebrand, ed. and translated by Elizabeth Schneewind (London: Routledge and Kegan Paul, 1973; originally published well after Brentano’s death in 1952).

Broad, C. D.: Five Types of Ethical Theory (London: Kegan Paul, Trench, Trubner \& Co., Ltd., 1930). 
Carson, Thomas L.: “Happiness, Contentment and the Good Life,” Pacific Philosophical Quarterly 62 (1981), pp. 378-392.

Chisholm, Roderick M.: Brentano and Intrinsic Value (Cambridge University Press, 1986).

Dancy, Jonathan: Moral Reasons (Oxford University Press, 1993).

Darwin, Charles: The Autobiography of Charles Darwin, Nora Barlow, ed. (New York: W. W. Norton, 1969).

Duncker, Karl: “On Pleasure, Emotion, and Striving,” Philosophy and Phenomenological Research 1 (1941), pp. 391-430.

Feldman, Fred (1): “Two Questions about Pleasure,” Philosophical Analysis: A Defense by Example, David Austin, ed. (Dordrecht: Reidel, 1988), pp. 59-81.

Feldman, Fred (2): Utilitarianism, Hedonism, and Desert (Cambridge University Press, 1997).

Feldman, Fred (3): “The Good Life: A Defense of Attitudinal Hedonism,” Philosophy and Phenomenological Research, vol. LXV, no. 3, November 2002, pp. 604-629.

Goldstein, Irwin (1): “Pain and Masochism,” Journal of Value Inquiry, 17 (1983), pp. 219-223.

Goldstein, Irwin (2): “Pleasure and Pain: Unconditional, Intrinsic Values,” Philosophy and Phenomenological Research, vol. 1, no. 2, December 1989, pp. 255-276.

Goldstein, Irwin (3): “Malicious Pleasure Evaluated: Is Pleasure an Unconditional Good?” Pacific Philosophical Quarterly 84 (2003), pp. 24-31.

Griffin, James: Well-Being: Its Meaning, Measurement and Moral Importance (Oxford University Press, 1986).

Haezrahi, Pepita: “Pain and Pleasure: Some Reflections on Susan Stebbing’s View That Pain and Pleasure Are Moral Values,” Philosophical Studies, vol. 11 (1960), pp. 71-78.

Hare, R. M.: Moral Thinking (Oxford University Press, 1981). 
Hutcheson, Francis: “A System of Moral Philosophy,” British Moralists, Vol. 1, L. A. SelbyBigge, ed. (Oxford University Press, 1897; originally published posthumously in 1755).

Kagan, Shelly: “The Additive Fallacy,” Ethics 99 (October 1988), pp. 5-31.

Kant, Immanuel: Grounding for the Metaphysics of Morals in Immanuel Kant: Ethical

Philosophy, translated by James W. Ellington (Indianapolis: Hackett Publishing Company, 1983; originally 1785).

Kraut, Richard: “Desire and the Human Good” (Presidential Address, Central Division Meeting), Proceedings and Addresses of the American Philosophical Association, November 1994, vol. 68, no. 2, pp. 39-54.

Lemos, Noah: Intrinsic Value: Concept and Warrant (Cambridge University Press, 1994).

Leibniz, Gottfried W.: New Essays on Human Understanding, translated and edited by Peter Remnant and Jonathan Bennett (Cambridge University Press, 1981; originally 1705).

Mayerfeld, Jamie: Suffering and Moral Responsibility (Oxford University Press, 1999).

Mill, John Stuart: Utilitarianism (1861), available in various reprintings.

Moore, G. E. (1): Principia Ethica, revised edition, Thomas Baldwin, ed. (Cambridge University Press, 1993; originally 1903).

Moore, G. E. (2): Ethics (London: Oxford University Press, 1912).

Nagel, Thomas: Mortal Questions (Cambridge University Press, 1979).

Nelkin, Norton: “Reconsidering Pain” Philosophical Psychology, vol. 7, no. 3 (1994), pp. 325343.

Oddie, Graham (1): “Axiological Atomism,” Australasian Journal of Philosophy, vol. 79, Issue 3 (September 2001), pp. 313-332.

Oddie, Graham (2): “Recombinant Values,” Philosophical Studies 106 (2001), pp. 259-292. 
O’Neill, John: “The Varieties of Intrinsic Value,” The Monist, vol. 75, no. 2 (April 1992), pp. 119-137.

Parfit, Derek: Reasons and Persons (Oxford University Press, 1984).

Perry, David L.: The Concept of Pleasure (The Hague: Mouton \& Co., 1967).

Plato: Plato: The Collected Dialogues, Edith Hamilton and Huntington Cairns, eds. (Princeton University Press, 1961; originally long ago).

Rachels, Stuart (1): A Theory of Beneficence, unpublished undergraduate thesis (University of Oxford, 1993).

Rachels, Stuart (2): “Counterexamples to the Transitivity of Better Than,” Australasian Journal of Philosophy 76 (1998), pp. 71-83.

Rachels, Stuart (3): “Is Unpleasantness Intrinsic to Unpleasant Experiences?” Philosophical Studies, vol. 99, no. 2, May (II) 2000, pp. 187-210.

Rachels, Stuart (4): “A Set of Solutions to Parfit’s Problems,” Nous, vol. 35, no. 2 (June 2001), pp. 214-238.

Rachels, Stuart (5): “Intransitivity,” Encyclopedia of Ethics, Vol. II, 2nd edition, Lawrence C. Becker, Mary Becker and Charlotte B. Becker, eds., (New York: Routledge, 2001), pp. 877-879.

Ross, W. D.: The Right and the Good (Indianapolis: Hackett Publishing Company, 1988; originally 1930).

Sacks, Oliver: The Man Who Mistook His Wife For a Hat And Other Clinical Tales (New York: Harper \& Row, 1987).

Schopenhauer, Arthur: The Basis of Morality, translated by A. Broderick Bullocks (London: Swan Sonneschein, 1903). 
Sidgwick, Henry: The Methods of Ethics, 7th ed. (Indianapolis: Hackett Publishing Company, 1906; reprinted in 1981).

Smart, J. J. C.: “An outline of a system of utilitarian ethics,” Utilitarianism for and against (with Bernard Williams) (Cambridge University Press, 1973).

Sprigge, T. L. S.: “The Greatest Happiness Principle,” Utilitas, vol. 3, no. 1, May 1991, pp. 3751.

Temkin, Larry S.: “A Continuum Argument for Intransitivity,” Philosophy and Public Affairs 25 (1996), pp. 175-210.

Yarnell, Patrick Y.: “The Intrinsic Goodness of Pain, Anguish, and the Loss of Pleasure,” Journal of Value Inquiry 35 (December 2001), pp. 449-454.

Zimmerman, Michael J. (1): (1980-81) “On the Intrinsic Value of States of Pleasure,” Philosophy and Phenomenological Research 41, pp. 26-45.

Zimmerman, Michael J. (2): “Virtual Intrinsic Value and the Principle of Organic Unities,” Philosophy and Phenomenological Research, vol. LIX, no. 3, September 1999, pp. 653666.

\footnotetext{
i Perry, p. 48. Perry also says that 'pleasure' can denote the fact that one has the prerogative to choose as one chooses.

${ }^{\text {ii }}$ Mayerfeld, p. 23. And see Sidgwick, p. 402, last paragraph.

iii Perry, p. 74.

iv See Feldman (2), ch. 5, p. 96 (chapter 5 originally appeared as Feldman (1)). Nelkin's view of pain is similar; see Nelkin.

v Sidgwick, p. 94.

${ }^{\text {vi }}$ Moore (1), p. 87 (ch. I, sect. 22).
} 
${ }^{\text {vii }}$ Moore (1), pp. 79-80 (ch. I, sect. 18).

viii See Kagan, Oddie (1) and Oddie (2).

${ }^{\text {ix }}$ Philosophers have often discussed whether certain limited classes of pleasures participate in organic unities (such as malicious pleasures and undeserved pleasures). See, for example, Zimmerman (2), pp. 653-654.

${ }^{x}$ See Rachels (3). On my view, the positive character of pleasures is intrinsic to their phenomenology.

${ }^{x i}$ But not accepted by Kraut. See Kraut, section VI (p. 46).

${ }^{\text {xii }}$ See Plato's Protagoras, 356b and 357 a-e; Mill, ch. V, fn., three paragraphs before the end; Sidgwick, p. 94, p. 121 and elsewhere; Moore (1), p. 130 (ch. III, sect. 47); Brandt (2), p. 255; Griffin, pp. 75, 104.

xiii Bentham, IV. V. 5. In the original, pleasure is italicized.

${ }^{\text {xiv }}$ Mill, ch. V, fn., three paragraphs before the end.

${ }^{x v}$ Sidgwick, p. 413; also see pp. 84, 94, 110, 123, 133, 381. Compare Griffin: "If the goodness of life consists in a lot of short-term pleasures or experiences, then to rank two courses of life we should clearly need to do a lot of totting-up.” (Griffin, p. 104)

${ }^{\text {xvi }}$ For related discussions, see Parfit, p. 431 and Mayerfeld, p. 65.

xvii See Rachels (1), (2), (4) and (5). Temkin defends a very similar argument in Temkin, based on Rachels (1) and drafts of Rachels (2).

xviii For discussion, see Mayerfeld, pp. 78-79 and Sprigge, p. 48.

${ }^{\text {xix }}$ Sprigge, p. 48.

${ }^{\mathrm{xx}}$ Compare Alston, p. 346; Brandt (2), p. 255; Hare, p. 123 (Hare gives credit to Griffin and Harsanyi). 
${ }^{x x i}$ See Sidgwick, chapters 2 and 3 of the second book.

xxii Sidgwick, pp. 142-143.

xxiii The existence of background pleasures, discussed in section 4, will create even more uncertainty and imprecision.

xxiv See Arntzenius and McCarthy. Initially, I was going to defend an additional thesis in this paper-that Quinn's puzzle of the self-torturer establishes the existence of sub-noticeable hedonic differences_-but then I discovered that Arntzenius and McCarthy had already defended this thesis beautifully. How disappointing that not a single author in the anthology on imperceptible benefits refers to their paper (see Almeida). It is always a shame when good papers get buried in the literature along with all of mine.

${ }^{\text {xxv }}$ Leibniz, p. 53. Leibniz says the "motion of a mill or a waterfall” on p. 53, but he means the sound that such motion makes; on p. 116 he refers to the water-mill's noise.

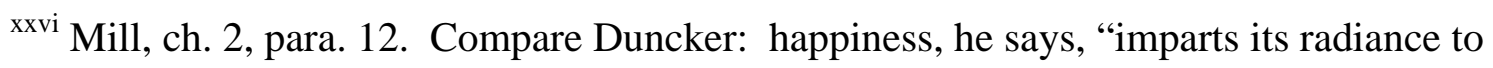
everything it happens to shine upon.” (p. 405)

xxvii Sidgwick, p. 179. Similarly, on p. 125 he says: “so long as health is retained, and pain and irksome toil banished, the mere performance of the ordinary habitual functions of life is, according to my experience, a frequent source of moderate pleasures, alternating rapidly with states nearly or quite indifferent.”

xxviii Sacks, p. 159.

${ }^{\text {xxix }}$ Plato, Philebus, 44a, translated by R. Hackforth in Plato. Socrates again condemns this idea in Plato’s Republic, Book IX, 583c-584c.

${ }^{\mathrm{xxx}}$ Darwin writes: "But pain or suffering, if long continued, causes depression and lessens the power of action; yet is well adapted to make a creature guard itself against any great or sudden 
evil. Hence it has come to pass that most or all sentient beings have been developed in such a manner through natural selection, that pleasurable sensations serve as their habitual guides.” (Darwin, p. 89)

${ }^{\text {xxxi }}$ Aristotle, VII. 14.

xxxii Nagel, p. 2 (this is in his essay, “Death”).

xxxiii Carson believes, similarly, that pleasure is bad if its object would be bad had it all the empirical characteristics which the person believes it to have. (pp. 388-389)

${ }^{\text {xxxiv }}$ Broad, p. 234.

${ }^{\text {xxxv }}$ Brentano (1), p. 90; Ross, pp. 136-137; Brandt (1), p. 316; Zimmerman (1), pp. 34-35;

Yarnell, p. 453; Feldman (3), especially p. 619.

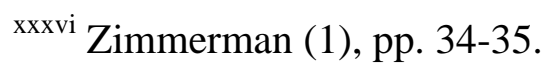

xxxvii Aristotle, X. 5. Dancy seems to agree: see Dancy, p. 61. Combining elements of (A) and (B), Haezrahi says, "pleasure and pain are morally neutral and dependent in their moral worth upon the moral standing of the thing or the activity they accompany.” (p. 72)

xxxviii Chisholm, p. 67. Chisholm refers us to Brentano (2), p. 172. Also, see Feldman (3), p.

619. Philosophers cite Plato's Republic in connection with (C), presumably referring to 585a-e, but there Plato doesn’t commit himself to anything much like (C).

xxxix This comes from the first paragraph of Kant (p. 7). Also see, for instance, Ross, p. 136 and Feldman (3), pp. 620-624.

${ }^{\mathrm{xl}}$ Lemos, p. 73.

xli Lemos, p. 46.

xlii Some philosophers say that pleasure’s being taken in a bad intentional object includes a bad intentional object (rather than entails its existence), but nothing important turns on this. 
xliii This is Brentano’s view. See Brentano (2), p. 196.

xliv Carson, p. 387. Carson actually writes, “I am convinced by the arguments of Brentano and others who hold that Schadenfreude is bad.”

${ }^{\text {xlv }}$ Zimmerman acknowledges that he has no argument on these matters. (Zimmerman (1), pp.

29, 35) Also see Moore (1), p. 258 (ch. VI, sect. 125); Ross, p. 137; Broad, p. 234; Haezrahi, pp. 74-75; Carson, p. 387; Chisholm, ch. 6; O’Neill, p. 132; Lemos, pp. 73-77.

${ }^{x l v i}$ For ease of expression I now say "pleasure is good" rather than "the existence of pleasure is good.”

xlvii Schopenhauer, pp. 156-157.

${ }^{x l v i i i}$ Although, as Smart says, “Our repugnance to the sadist arises, naturally enough, because in our universe sadists invariably do harm. If we lived in a universe in which by some extraordinary laws of psychology a sadist was always confounded by his own knavish tricks and invariably did a great deal of good, then we should feel better disposed towards the sadistic mentality.” (pp. 25-26)

${ }^{\text {xlix }}$ Goldstein exposes other bad reasons to condemn the pleasures of schadenfreude in Goldstein (3).

${ }^{1}$ Goldstein (2), p. 269. Lemos gives the same argument (pp. 43-44). Goldstein gives a similar argument for the badness of deserved pain in Goldstein (1), p. 221.

li Several philosophers who disbelieve this argument's conclusion accept this premise: Zimmerman (1), p. 31; Carson, p. 387; Chisholm, p. 66; Lemos, p. 76 (on this page see (7): "Pleasure in the merely neutral is intrinsically good"). 
lii Compare Goldstein: "Since at least some pleasure is good intrinsically simply because of its pleasurableness, pleasure should always be good intrinsically, whatever the society, and so be an unconditional value.” (Goldstein (2), p. 273)

liii Here I am not assuming that the pleasure's “feel” or "what it's like” is strictly a matter of phenomenology.

${ }^{\text {liv Mill, ch. 2, para. } 6 .}$

${ }^{\mathrm{lv}}$ Mill himself mentions these last three. (ch. 2, para. 6)

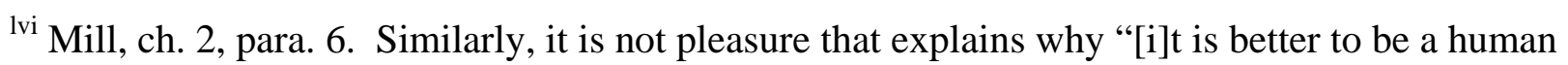
being dissatisfied than a pig satisfied; better to be Socrates dissatisfied than a fool satisfied.” (ch. 2, para. 6)

${ }^{\text {lvii }}$ Mill, ch. 2, para. 6 .

lviii See Moore (2), pp. 146-147.

${ }^{\text {lix }}$ Hutcheson, pp. 421-422.

${ }^{\mathrm{lx}}$ I thank the Research Advisory Committee of the University of Alabama for a grant that helped fund this work. 